\title{
Ausência do homem no pré-natal da parceira e no pré-natal do pai
}

\author{
Absence of man in the partner's prenatal care and father's prenatal care
}

\author{
Ausencia del hombre en la atención prenatal de la pareja y la atención prenatal del padre
}

\begin{abstract}
Arianne Cardozo Bueno ${ }^{1 *}$, Elisângela do Nascimento Fernandes Gomes ${ }^{2}$, Alessandra da Silva Souza ${ }^{3}$, Jannaína Sther Leite Godinho Silva ${ }^{4}$, Geísa Sereno Velloso da Silva ${ }^{5}$, Thiago Augusto Soares Monteiro da Silva ${ }^{6}$
\end{abstract}

Como citar esse artigo. Bueno, AC; Gomes, ENF; Souza, AS; SIlva, JSLG; da Silva, GSV; da Silva, TASM. Ausência do homem no Pré-Natal da Parceira e no Pré-Natal do pai. Revista Pró-UniverSUS. 2021 Jul./Dez.; 12 (2) SUPLEMENTO: 39 - 46

\begin{abstract}
Resumo
Tradicionalmente, o planejamento reprodutivo e as atividades em saúde referentes ao momento da gestação, parto e puerpério, eram voltadas apenas às mulheres, entretanto em 2011 o Ministério da Saúde (MS) normatizou o Programa de Pré-Natal do Homem, com vistas a reagir contra a desigualdade, estimulando a prática de uma paternidade mais ativa e cuidadora, além da prevenção de patologias. Dessa forma o trabalho tem o intuito de analisar a adesão do pai no acompanhamento do pré-natal da mulher e na realização do pré-natal do parceiro. Trata-se de um estudo de revisão integrativa, descritiva e exploratória na qual foi selecionado base de dados BIREME, MEDLINE, LILACS e BDENF no recorte dos últimos 5 anos. Os estudos indicam a ausencia do homem nos serviços de saúde, quando há inclusão do homem no acompanhamento do pré-natal, sua presença não é efetiva, a participação destes sucede passivamente, pois apontam o parceiro como ouvinte da assistência prestada à mulher, sua presença não ocorre de maneira ativa. Os fatores que contribuem para ausencia dos homens são: incompatibilidade no horário de atenedimento das unidades de saúde, fragilidade na capacitação dos profissioanais e desconhecimento do homem sobre seus direitos. Espera-se que os dados da pesquisa possa contribuir, para a reeorganização e reformulação no planejamento dos serviços, para ampliar a qualidade do atendimento, da saúde do homem e da adesão do pai no pré-natal da mulher e no pré-natal do homem.

Palavras-chave: Enfermagem; Paternidade; Pré-Natal.
\end{abstract}

\begin{abstract}
Traditionally, reproductive planning and health activities related to the time of pregnancy, childbirth and the puerperium, were aimed only at women, however in 2011 the Ministry of Health (MS) standardized the Man's Prenatal Program, in order to react against inequality, encouraging the practice of a more active and caring parenting, in addition to the prevention of pathologies. Thus, the work aims to analyze the father's adherence in monitoring the woman's prenatal care and in carrying out the partner's prenatal care. This is an integrative, descriptive and exploratory review study in which the BIREME, MEDLINE, LILACS and BDENF database was selected in the last 5 years. Studies indicate the absence of men in health services, when men are included in prenatal care, their presence is not effective, their participation happens passively, as they point out the partner as a listener of the assistance provided to women, their presence it does not occur actively. The factors that contribute to the absence of men are: incompatibility in the opening hours of health units, fragility in the training of professionals and the lack of knowledge of men about their rights. It is hoped that the research data can contribute to the reorganization and reformulation in service planning, to increase the quality of care, men's health and father's adherence in women's prenatal and men's prenatal care.
\end{abstract}

Keywords: Nursing; Paternity; Prenatal.

Afiliação dos autores:

1*Acadêmica de Enfermagem pela Universidade de Vassouras, RJ, Brasil. E-mail: ariiannec@gmail.com ORCID: https://orcid.org/0000-0003-0968-7024

${ }^{2}$ Mestre. Docente do Curso de Enfermagem, Universidade de Vassouras. RJ, Brasil. E-mail: elisangelavass@yahoo.com.br ORCID: http://orcid.org/0000-0001-8432-4157

${ }_{3}^{3}$ Mestre. Docente do Curso de Enfermagem, Universidade de Vassouras. RJ, Brasil. E-mail: alesouza22@yahoo.com.br ORCID: https://ORCID.org/0000-0002.9009-9774

${ }^{4}$ Mestre. Docente do Curso de Enfermagem, Universidade de Vassouras. RJ, Brasil. E-mail: jjasther@gmail.com ORCID: https://orcid.org/0000-0002-8308-2093

${ }^{5}$ Mestre. Docente do Curso de Enfermagem, Universidade de Vassouras. RJ, Brasil. Email: geisa.velloso@hotmail.com ORCID: https://orcid.org/0000-0003-0304-8010

${ }^{6}$ Doutor. Docente do curso de Enfermagem, Universidade de Vassouras. RJ, Brasil, E-mail: thiagoams@bol.com.br ORCID: https://orcid.org/0000-0001-6870-5101 


\section{Resumen}

Tradicionalmente, las actividades de planificación y salud reproductiva relacionadas con el momento del embarazo, parto y puerperio, estaban dirigidas únicamente a las mujeres, sin embargo, en 2011 el Ministerio de Salud (MS) estandarizó el Programa Prenatal del Hombre, con el fin de reaccionar contra la desigualdad, fomentando la práctica de una crianza más activa y solidaria, además de la prevención de patologías. Así, el trabajo tiene como objetivo analizar la adherencia del padre en el seguimiento de la atención prenatal de la mujer y en la realización de la atención prenatal de la pareja. Se trata de un estudio de revisión integrador, descriptivo y exploratorio en el que se seleccionó la base de datos BIREME, MEDLINE, LILACS y BDENF en los últimos 5 años. Los estudios señalan la ausencia de los hombres en los servicios de salud, cuando se incluye a los hombres en la atención prenatal, su presencia no es efectiva, su participación se da de manera pasiva, ya que señalan a la pareja como oyente de la asistencia brindada a las mujeres, su presencia no ocurre activamente. Los factores que contribuyen a la ausencia de los hombres son: la incompatibilidad en los horarios de atención de las unidades de salud, la fragilidad en la formación de los profesionales y el desconocimiento de los hombres sobre sus derechos. Se espera que los datos de la investigación puedan contribuir a la reorganización y reformulación en la planificación de servicios, para aumentar la calidad de la atención, la salud de los hombres y la adherencia del padre en la atención prenatal de mujeres y hombres.

Palabras clave: Enfermería; Paternidad; Prenatal.

\section{Introdução}

Outrora, a mulher e seu corpo só eram vistos e reconhecidos pela função reprodutiva e materna, limitando - se a isso ou à ausência de enfermidades relacionadas ao processo de reprodução biológica, excluindo os direitos sexuais e as demandas de gênero que eram pautadas na construção social - sobreposta a um corpo sexuado, e histórica. Tal construção era pautada por símbolos, normas e instituições que definiam a masculinidade e feminilidade, os padrões de comportamentos aceitáveis e delimitava os campos de atuação para cada sexo. ${ }^{1}$

Para a maior parte dos casais o período gravídico se configura como um dos melhores momentos vivenciados. Tradicionalmente, o planejamento reprodutivo e as atividades em saúde referentes ao período da gestação, parto e puerpério, eram voltadas apenas às gestantes. Culturalmente, muitos acreditam que essa fase é exclusiva para as mulheres, visto que fisiologicamente elas são as protagonistas, entretanto, sabe-se atualmente que seu parceiro deve atuar de forma relevante, para estimular possuímos como ferramenta o acompanhamento pré-natal, a presença do acompanhante neste atendimento é de suma importância nessa fase, pois constrói um vínculo com o bebê e compreende sobre a gestação. ${ }^{1}$

Com a confirmação da gravidez, inicia-se a rotina do pré-natal, pelo Ministério da Saúde recomenda-se no mínimo seis consultas, nelas a gestante e o parceiro recebem orientações necessárias para o desenvolvimento saudável da gestação, é realizado exame físico, testes rápidos, exames laboratoriais, exames de imagem, e encaminhamentos a outros serviços, caso necessário. ${ }^{2}$

Em junho de 2011, os diretos relativos deste o controle reprodutivo até a atenção humanizada à gravidez, a concepção e ao puerpério, e ainda, o nascimento seguro e o crescimento e desenvolvimento saudáveis do bebê, foram assegurados e reestruturados de forma a organizar a atenção a saúde materna - infantil. Tal rede, abrange vários serviços, dentre eles, a oferta de exames e possui como um de seus componentes a assistência ao longo do ciclo gestacional. ${ }^{3}$

Além disso, as consultas realizadas antes do parto, sustentam uma boa condição de saúde do binômio, bem como de proporcionar à mulher uma boa experiência de vida nessa fase. Desta forma, é primordial que os comprometidos em qualquer âmbito da fase de assistência estejam cientes da importância do seu desempenho e da indispensabilidade de harmonizar o conhecimento técnico especifico a premissa de obter um resultado suficiente de atenção, prezando pelo o que o resultado expressa para a mulher. ${ }^{4}$

Em 2016 foi lançado um documento que discorre a respeito do pré-natal masculino, um projeto pioneiro do Hospital das Clínicas da Faculdade de Medicina de Ribeirão Preto (SP), implantado em 2007, que atualmente faz parte das ações da Política Nacional de Saúde do Homem do Ministério da Saúde, instituída em 2009. Posteriormente, o Programa Pré-natal do Homem foi normatizado com vistas a reagir contra a desigualdade, estimulando a prática de uma paternidade mais ativa e cuidadora, antes, durante e depois do nascimento, além da prevenção de patologias. Para que ocorra a efetivação do pré-natal masculino é substancial que as unidades de atenção básica dos municípios busquem sua implementação. ${ }^{5}$

O programa tem a finalidade de incentivar os homens quanto a promoção e a prevenção em saúde, pois, no geral, eles não possuem o hábito de ir às consultas periodicamente, como é o caso das mulheres. Por isso, quando presente na unidade de saúde para a consulta de pré-natal, o parceiro será submetido a testes rápidos e terá a carteira de vacinação avaliada e atualizada, bem como direcionado para realizar a sorologia para hepatite $\mathrm{B}$ e C, HIV e sífilis e exames laboratoriais relacionados a diabetes, colesterol e pressão arterial. $^{5}$

O mesmo irá obter informações acerca do risco e 
a prevenção das infecções sexualmente transmissíveis, posto que, a diminuição do risco de transmissão vertical de alguma doença, ou seja, a transmissão de mãe para filho, é importante a adesão do parceiro ao tratamento, se diagnosticado com sífilis e HIV, e sobre a eventualidade de ser submetido a cirurgia de vasectomia se o casal decidir a respeito, e se necessário, são solicitados consultas complementares e outros exames preventivos, como o de próstata. ${ }^{5}$

O acompanhamento do parceiro busca inserir o homem no binômio mãe e bebê desde cedo para auxiliar e agregar no desempenho da paternidade, para isso, conta com atividades educativas e ações que são básicas para o cuidado diário do bebê, como troca de fraldas e banho. É recomendado também incentivá-los a participar de grupos de assuntos acerca da masculinidade, gênero, saúde sexual e reprodutiva, paternidade e cuidado, hábitos saudáveis, prevenção de violência e de acidentes e direitos legais dos pais. ${ }^{6}$

Embora exista atualmente facilidade no acesso a saúde para implementação da estratégia, ainda é expressivo o número de homens que não frequentam as consultas de pré-natal junto as gestantes. ${ }^{7}$ Diante do exposto surgiu os seguintes questionamentos: Quais são os fatores para a ausência do homem no acompanhamento do Pré-Natal da Mulher e na realização do Pré-Natal do Parceiro. Para responder estas questões foi estabelecido o seguinte objetivo geral analisar a adesão do Pai no Acompanhamento do Pré-Natal da mulher e na realização do Pré-Natal do Parceiro.

\section{Metodologia}

Trata-se de um estudo de revisão integrativa de literatura, descritiva e exploratória com o intuito de reunir ordenadamente informações sobre a temática para que posteriormente sejam contextualizadas e proporcionem resultados acerca das buscas sobre o tema em questão. A finalidade é analisar uma informação anteriormente evidenciada sobre algum assunto. Também oportuniza o apanhado de estudos difundidos, proporcionando novos pensamentos, elencados anteriormente por outros estudos. ${ }^{8}$

A revisão integrativa é considerada um recurso típico com o intuito de resumir o passado da literatura empírica ou teórica, com vistas a prover um entendimento mais irrestrito. Dá -se após as seguintes fases: $1^{\text {a }}$ concretização da hipótese ou questão norteadora; $2^{\text {a }}$ levantamento dos critérios de inclusão e exclusão dos estudos; $3^{\text {a }}$ coleta de dados com a delimitação das informações que serão extraídas e categorizadas; $4^{\text {a }}$ exploração dos estudos englobados; $5^{\text {a }}$ análise das repercussões encontradas e $6^{\text {a }}$ apresentação da reavaliação da revisão integrativa. ${ }^{8}$

Os estudos observacionais descritivos são definidos como aqueles que buscam indicar as particularidades das amostras encontradas sem que haja algum vínculo entre elas. Sua relevância está no fato de indicar o ordenamento das patologias ou condições pertinentes a saúde de acordo com o tempo, localidade e/ou peculiaridades do sujeito. ${ }^{9}$

A pesquisa qualitativa busca compreender os significados, as falas e os comportamentos dos sujeitos dentro do contexto que estão inseridos, de modo que enfatize a qualidade e não se contrasta a alcançar a representatividade. ${ }^{10}$ Já, outro autor refere que a pesquisa qualitativa em saúde opera com o conjunto de significados, motivações, aspirações, crenças, valores e atitudes, o que condiz com as questões envolvidas das relações, processos e dos fenômenos que não podem ser reduzidos à operacionalização de variáveis. ${ }^{11}$

A princípio foi realizado a primeira etapa da pesquisa, na qual foi estabelecido o tema: desafios do pré-natal do parceiro na Estratégia Saúde da Família, e a definição da questão norteadora do estudo: Quais são os fatores para a ausência do homem no acompanhamento do Pré-Natal da Mulher e na realização do Pré-Natal do Parceiro. Iniciou-se a reunião dos dados em outubro de 2020 na base de dados BIREME - Centro Latino Americano e do Caribe de Informação em Ciências da Saúde, MEDLINE - Medical Literature Analysis and Retrievel System Online, LILACS - Literatura LatinoAmericana e do Caribe em Ciências da Saúde e BDENF - Base de Dados de Enfermagem, sendo explorados cautelosamente até janeiro de 2021.

Os critérios de inclusão empregados relacionavam-se a estudos publicados nos últimos cinco anos, dos quais abrangessem trabalhos científicos relacionados ao tema em pauta; artigos com textos completos disponíveis na íntegra das bases de dados online relacionados aos profissionais de enfermagem. Os critérios de exclusão foram: artigos que não fizessem parte do recorte temporal delimitado, estudos incompletos e que não estivessem disponíveis na base de dados e aqueles que não contemplassem a temática ou que não correspondente a questão norteadora.

Para analisar o conteúdo dos estudos encontrados aplicou-se um instrumento de coleta de dados constando os subsequentes itens: ano em que foi publicado, metodologia aplicada e resultados dispostos. A avaliação dos artigos elegidos sucede exaustivamente de maneira estruturada e apreciativa, proporcionando com que os dados acerca do assunto fossem elucidados.

\section{Resultados}

Foram encontrados cento e dezenove (119) artigos, desses, doze (12) integram os critérios de inclusão, porém, três (3) foram descartados devido a 


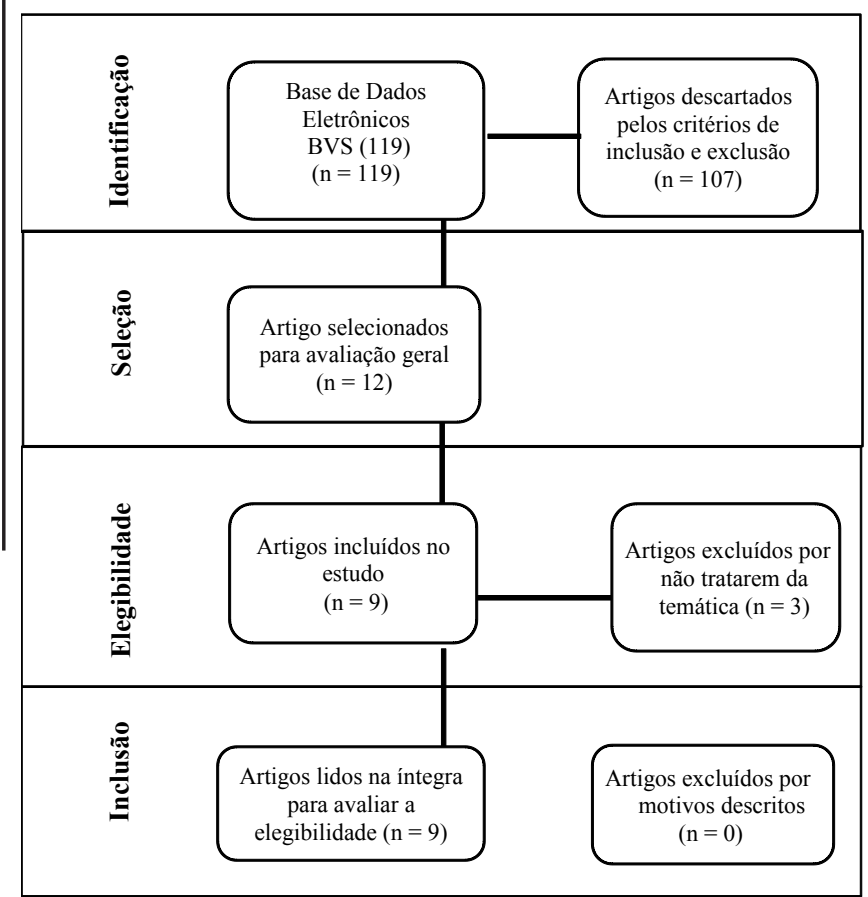

Figura 1. Fluxograma de apuração dos estudos incorporados na revisão integrativa de acordo com as bases de dados. Rio de Janeiro, RJ, Brasil, (2020).

Fonte: Os autores (2021).

incompatibilidade com o assunto em questão totalizando nove (9) estudos para análise. O quadro 1 , em seguida, contempla e evidencia os estudos encontrados a partir do número, título, país, ano de publicação, tipo de abordagem, objetivo, resultados principais.
Através dos trabalhos explorados, constatou-se que todos foram elaborados no Brasil, sendo oito (8) publicados com idioma português e um (1) na língua inglesa, ainda, destes, um artigo é de 2020, um artigo de 2019, um de 2018, três artigos de 2017, dois de 2016 e um de 2015. Em relação aos tipos de estudos revelouse a maioria dos estudos descritivos. Sobre o tipo de abordagem metodológica, grande parte configurou-se de natureza qualitativa, meramente um artigo determinado como quantitativo e outro quanti-qualitativo.

\section{Discussão}

A partir da análise documental os trabalhos foram reunidos em três grupos, a saber: adesão do pai no acompanhamento do pré-natal da parceira e na realização do pré-natal do pai, fatores que influenciam a ausência do homem no pré-natal da parceira e na realização do pré-natal do pai e as estratégias para a adesão do pai no pré-natal do parceiro.

\section{Adesão do pai no acompanhamento do pré-natal da parceira e na realização do pré-natal do pai.}

Após análise, a maioria dos artigos evidenciaram a inclusão do parceiro nas consultas de pré-natal das gestantes, porém, a participação destes sucedeu passivamente, pois apontam o parceiro como ouvinte da assistência prestada à mulher, ou seja, sua presença

Quadro 1. Descrição dos escritos primários incluídos no estudo, Rio de Janeiro, RJ, Brasil, 2020.

\begin{tabular}{|c|c|c|c|c|c|c|}
\hline $\mathbf{N}^{\mathbf{o}}$ & TÍTULO & PÁIS & ANO & $\begin{array}{c}\text { TIPO DE } \\
\text { ABORDAGEM }\end{array}$ & OBJETIVOS & RESULTADOS PRINCIPAIS \\
\hline 1 & $\begin{array}{l}\text { Participação do pai } \\
\text { jovem no acom- } \\
\text { panhamento do } \\
\text { pré-natal: a visão } \\
\text { do profissional de } \\
\text { saúde. }\end{array}$ & Brasil & 2020 & $\begin{array}{l}\text { Pesquisa docu- } \\
\text { mental com abor- } \\
\text { dagem qualitativa, }\end{array}$ & $\begin{array}{l}\text { Conhecer a visão dos en- } \\
\text { fermeiros/as e médicos/as } \\
\text { sobre a paternidade na ado- } \\
\text { lescência; identificar ações } \\
\text { direcionadas ao jovem pai } \\
\text { no pré-natal. }\end{array}$ & $\begin{array}{l}\text { As participantes declararam a diferença } \\
\text { entre ser pai jovem e adulto, destacando- } \\
\text { se a maturidade. A maioria condenou a } \\
\text { gravidez na adolescência, e a não-frequ- } \\
\text { ência dos pais às consultas. }\end{array}$ \\
\hline 2 & $\begin{array}{l}\text { Participação Paterna } \\
\text { no Ciclo Gravídico- } \\
\text { Puerperal e seus } \\
\text { efeitos sobre a saú- } \\
\text { de da mulher. }\end{array}$ & Brasil & 2019 & $\begin{array}{l}\text { Revisão integra- } \\
\text { tiva realizada nas } \\
\text { bases de dados } \\
\text { LILACS, MEDLI- } \\
\text { NE e CINAHL. }\end{array}$ & $\begin{array}{l}\text { Buscar evidencias cienti- } \\
\text { ficas sobre a participação } \\
\text { paterna no processo de ges- } \\
\text { tação, parto, nascimento e } \\
\text { puerpério, } \\
\text { relacionando-os com os } \\
\text { seus efeitos para a saúde da } \\
\text { mulher. }\end{array}$ & $\begin{array}{l}\text { Foram selecionados } 9 \text { artigos e agrupados } \\
\text { em três momentos } \\
\text { do ciclo gravídico-puerperal onde houve } \\
\text { intervenção paterna com vistas a melhor } \\
\text { qualidade no apoio e acompanhamento } \\
\text { da } \\
\text { mulher. }\end{array}$ \\
\hline 3 & $\begin{array}{l}\text { A Participação do } \\
\text { Parceiro na Roti- } \\
\text { na Pré-Natal Sob a } \\
\text { Perspectiva da Mu- } \\
\text { lher Gestante }\end{array}$ & Brasil & 2018 & $\begin{array}{l}\text { Estudo descritivo } \\
\text { exploratório de } \\
\text { abordagem quali- } \\
\text { tativa. }\end{array}$ & $\begin{array}{l}\text { Analisar como a gestante } \\
\text { percebe a participação do } \\
\text { parceiro na rotina pré-natal. }\end{array}$ & $\begin{array}{l}\text { Das participantes do estudo, apenas uma } \\
\text { teve acompanhamento integral do parcei- } \\
\text { ro, outras cinco relataram a presença ape- } \\
\text { nas na realização da ultrassonografia obs- } \\
\text { tétrica. Daquelas que relataram ausência, } \\
\text { o trabalho foi apontado como principal } \\
\text { fator, também se observou que questões } \\
\text { de gênero influenciam nesta ausência, } \\
\text { pois a gestação é vista como momento } \\
\text { exclusivo da mulher. }\end{array}$ \\
\hline
\end{tabular}


Quadro 1 (cont.). Descrição dos escritos primários incluídos no estudo, Rio de Janeiro, RJ, Brasil, 2020.

\begin{tabular}{|c|c|c|c|c|c|c|}
\hline $\mathbf{N}^{\mathbf{0}}$ & TÍTULO & PÁIS & ANO & $\begin{array}{c}\text { TIPO DE } \\
\text { ABORDAGEM }\end{array}$ & OBJETIVOS & RESULTADOS PRINCIPAIS \\
\hline 4 & $\begin{array}{l}\text { A visão das gestan- } \\
\text { tes acerca da parti- } \\
\text { cipação do homem } \\
\text { no processo gesta- } \\
\text { cional. }\end{array}$ & Brasil & 2017 & $\begin{array}{l}\text { Trata-se de uma } \\
\text { pesquisa qualita- } \\
\text { tiva, avaliada por } \\
\text { meio de análise de } \\
\text { conteúdo. }\end{array}$ & $\begin{array}{l}\text { Analisar a visão das gestan- } \\
\text { tes quanto à participação do } \\
\text { homem durante o processo } \\
\text { gestacional e as consultas } \\
\text { de pré-natal. }\end{array}$ & $\begin{array}{l}\text { A pesquisa apontou o apoio ofertado em } \\
\text { âmbito familiar como essencial para a } \\
\text { gestante e a ausência do homem durante } \\
\text { a consulta foi entendida e justificada pelo } \\
\text { horário de trabalho do companheiro, na } \\
\text { maioria das vezes. }\end{array}$ \\
\hline 5 & $\begin{array}{l}\text { Atenção à gestante } \\
\text { adolescente na rede } \\
\text { SUS - o acolhimen- } \\
\text { to do parceiro no } \\
\text { pré-natal. } \\
\end{array}$ & Brasil & 2017 & $\begin{array}{l}\text { Estudo descriti- } \\
\text { vo, de abordagem } \\
\text { qualitativa. }\end{array}$ & $\begin{array}{l}\text { Verificar o acolhimento e a } \\
\text { participação de parceiros de } \\
\text { gestantes adolescentes no } \\
\text { pré-natal da rede SUS. }\end{array}$ & $\begin{array}{l}\text { Houve o desejo do parceiro de acompa- } \\
\text { nhar as consultas do pré-natal, mas este } \\
\text { desconhece seu direito de participar. Há } \\
\text { limites pessoais e institucionais para efe- } \\
\text { tivar a participação dos parceiros. }\end{array}$ \\
\hline 6 & $\begin{array}{l}\text { A participação do } \\
\text { pai no processo de } \\
\text { amamentação. }\end{array}$ & Brasil & 2017 & $\begin{array}{l}\text { Pesquisa descriti- } \\
\text { va de abordagem } \\
\text { quantitativa. }\end{array}$ & $\begin{array}{l}\text { Identificar a participação do } \\
\text { pai no processo de amamen- } \\
\text { tação em uma maternidade } \\
\text { estadual da região centro- } \\
\text { oeste do Brasil. }\end{array}$ & $\begin{array}{l}\text { O principal fator facilitador para os pais } \\
\text { ajudarem na amamentação foi a vontade } \\
\text { de apoiar a esposa } 37(66,08 \%) \text { e o difi- } \\
\text { cultador, conciliar o horário de trabalho, } \\
19(33,93 \%) \text {. Estar junto da mulher é a } \\
\text { maneira que os pais encontraram para } \\
\text { favorecer a amamentação e sua participa- } \\
\text { ção é fundamental para o sucesso desse } \\
\text { processo. }\end{array}$ \\
\hline 7 & $\begin{array}{l}\text { A inclusão paterna } \\
\text { durante o pré-natal. }\end{array}$ & Brasil & 2016 & $\begin{array}{l}\text { Trata-se de uma } \\
\text { pesquisa } \text { com } \\
\text { abordagem quali- } \\
\text { tativa e de caráter } \\
\text { descritivo e explo- } \\
\text { ratório. }\end{array}$ & $\begin{array}{l}\text { Investigar a participação } \\
\text { paterna durante o pré-natal } \\
\text { em um Centro de Atenção à } \\
\text { Saúde da Mulher. }\end{array}$ & $\begin{array}{l}\text { A limitação da oferta de horários de aten- } \\
\text { dimento, que coincidem com os de traba- } \\
\text { lho dos homens dificulta a participação } \\
\text { paterna. Destacou-se a importância de as } \\
\text { gestantes encorajarem o seu parceiro a } \\
\text { participar das atividades do pré-natal. }\end{array}$ \\
\hline 8 & $\begin{array}{l}\text { Linhas de cuidados } \\
\text { masculinos voltados } \\
\text { para a saúde sexual, } \\
\text { a reprodução e a pa- } \\
\text { ternidade. }\end{array}$ & Brasil & 2015 & $\begin{array}{l}\text { O estudo consiste } \\
\text { num trabalho opi- } \\
\text { nativo que parte } \\
\text { da experiência } \\
\text { dos autores e, em } \\
\text { seguida, busca a } \\
\text { sua validação por } \\
\text { especialistas no } \\
\text { assunto, amplian- } \\
\text { do assim o fórum } \\
\text { de opiniões com } \\
\text { vista a alcançar } \\
\text { um consenso. }\end{array}$ & $\begin{array}{l}\text { Objetiva propor princípios } \\
\text { para os cuidados mascu- } \\
\text { linos voltados para a saú- } \\
\text { de sexual, a reprodução e } \\
\text { a paternidade, bem como } \\
\text { apresentar um fluxo para o } \\
\text { envolvimento de homens no } \\
\text { pré-natal. }\end{array}$ & $\begin{array}{l}\text { Como resultados, são apresentados (a) os } \\
\text { princípios das linhas de cuidados mascu- } \\
\text { linos voltados para a saúde sexual, a re- } \\
\text { produção e a paternidade, e (b) proposta } \\
\text { de fluxo de envolvimento de homens no } \\
\text { pré-natal. }\end{array}$ \\
\hline 9 & $\begin{array}{l}\text { E agora o homem } \\
\text { vem?! Estratégias } \\
\text { de atenção à saúde } \\
\text { dos homens. }\end{array}$ & Brasil & 2016 & $\begin{array}{l}\text { Seu desenho me- } \\
\text { todológico foi de } \\
\text { caráter misto, aqui } \\
\text { entendido como } \\
\text { a combinação de } \\
\text { métodos, aborda- } \\
\text { gens e técnicas de } \\
\text { perspectivas qua- } \\
\text { litativa e quantita- } \\
\text { tiva em um único } \\
\text { estudo. }\end{array}$ & $\begin{array}{l}\text { Compreender as estratégias } \\
\text { de atenção à saúde dos ho- } \\
\text { mens segundo a ótica de } \\
\text { profissionais de saúde. }\end{array}$ & $\begin{array}{l}\text { A partir da compreensão do conjunto } \\
\text { dos depoimentos, foram identificados } \\
\text { três eixos, independentemente da temá- } \\
\text { tica abordada (sexualidade masculina, } \\
\text { envolvimento de homens no pré-natal } \\
\text { paternidade) e da região. Os eixos são es- } \\
\text { truturantes e estruturados por ideias que } \\
\text { permeiam os diferentes depoimentos. Os } \\
\text { temas sexualidade masculina em associa- } \\
\text { ção com paternidade e cuidado à saúde } \\
\text { ainda evocam a dimensão privada, referi- } \\
\text { da aos limites da geografia da casa. }\end{array}$ \\
\hline
\end{tabular}

Fonte: Dados sa pesquisa.

não ocorre de maneira ativa, uma vez que o mesmo, na maioria das vezes não possuem oportunidade de relatar informações pertinentes sobre sua saúde, assim como, não é envolvido pelos profissionais no atendimento e procedimentos realizados. Perante ao exposto, nota-se que a inclusão paterna no pré-natal da parceira e pré-natal do pai é insuficiente, apesar dos esforços e da presença de alguns homens. De acordo com essas informações, podemos observar que é essencial a mudança da postura do profissional mediante a presença do homem nas consultas de pré-natal, fica evidente a necessidade de capacitação e sensibilização do profissional para 
inclusão de forma efetiva para realização do pré-natal da parceira como para o pré-natal do pai. ${ }^{12,13,14,15,18,20 .}$

Dentre os aspectos referidos pelos companheiros para que estivessem presente neste momento, o apoio da esposa foi fundamental seguido do fato de conseguirem conciliar o horário de trabalho com os dos atendimentos, sabe-se que isso não é uma realidade para todos os homens. A maioria dos envolvidos narraram que testemunharam as consultas de pré-natal com as gestantes consequentemente isso demonstra uma modificação na atitude paterna. ${ }^{17}$

Os demais artigos apontam a ausência do homem nos serviços ofertados pelas unidades de saúde, tanto em relação a saúde materna quanto a paterna. Essa informação é um indicador negativo de saúde, pois dificulta o diagnóstico precoce e tratamento de patologias e infecções, tendo como consequência o aumento dos índices de doenças no período gravídico e transmissão vertical, que podem causar várias complicações, como aborto, parto prematuro, doenças congênitas ou morte do recém-nascido. Quando os parceiros acompanham as gestantes, configura-se como a chance de inclui-los na prevenção de doenças e agravos, além de, intensificar os meios para proceder com os exames clínicos de rotina, reconhecer a presença do pai durante as consultas de pré-natal e inseri-los no planejamento familiar. ${ }^{20,21}$

A presença do parceiro nas consultas é vista positivamente, tornando-as mais completas de forma a contribuir para o melhor entendimento das orientações por estarem atentos e interessados. Neste momento o pai terá oportunidade de conhecer os processos relacionados acerca do período gestacional, alterações fisiológicas e emocionais da parceira, será motivado para participar nas tomadas de decisões e na divisão de responsabilidades. Vivenciar a gravidez pode proporcionar ao pai sentimentos afetuosos e vínculos significativos para o trinômio pai-mãe-filho. ${ }^{12,13,14}$

Fatores que influenciam a ausência do homem no pré-natal da parceira e na realização do pré-natal do pai.

A ausência do homem nos serviços de saúde, não é um tema recente e ainda está longe de se esgotar, dos artigos analisados, três deles apresentam motivos pelos quais os homens dificilmente procuram os serviços de promoção e prevenção à saúde na atenção básica, corroborando com a ideia de que cuidam menos de sua saúde e a principal porta de entrada para tal público são os serviços especializados, como por exemplo, a rede de urgência e emergência. ${ }^{14,15,16}$

Em contrapartida, tal ausência está relacionada, segundo os estudos científicos, ao fluxo e forma de atendimento ofertados, pode-se observar uma ineficiência do funcionamento dos serviços oferecidos, que simulam um dos obstáculo para o comparecimento masculino às unidades de saúde, problemas para agendamento das consultas, o horário de funcionamento, as filas e a falta de segurança de que os problemas serão resolvidos, estrutura física inadequada e despreparada, esses motivos são decisivos para a ausência masculina na atenção básica de saúde, fazendo com que os homens procurem o atendimento de emergência, por apresentarem um atendimento rápido e objetivo. ${ }^{14,16,18}$

Tal explanação expõe o desconhecimento do direito da participação paterna na assistência realizada no período gravídico. As Unidades de Saúde devem ajustar, criar horários alternativos, para o atendimento desta população, de forma a garantir o direito do homem no acompanhamento da parceira e realização do prénatal do pai. ${ }^{14,16}$

Os homens desconhecem seus direitos, não sabem que existe uma política pública de saúde voltadas para os homens e políticas públicas para a primeira infância que dá o direito de acompanhamento do pré-natal da parceira. Essa informação, também justifica a ausência do homem na unidade Básica de Saúde, já que os mesmos não tendo conhecimento de seus direitos como poderão exigi-lo. ${ }^{14,15,16}$

A Lei $n^{0}$ 13.257/2016 de 08 de março de 2016, dispõe sobre as políticas públicas para a primeira infância, engloba no artigo 473 da CLT que o trabalhador poderá se ausentar até 2 (dois) dias para acompanhar consultas médicas e exames complementares durante o período de gravidez de sua esposa ou companheira. ${ }^{22}$

Outra situação ponderada é a escolha da gestante de não ter o acompanhante participando da rotina de consultas, por acreditar ser um momento privativo da mulher com o profissional envolvido. Alegam que a presença do companheiro possa interferir na sua autonomia, retornando ao passado em que muitas mulheres eram submissas a seus companheiros culturalmente, religiosamente e moralmente. ${ }^{14,15}$

Outrossim, é muito comum os serviços de saúde voltarem sua atenção para as mulheres e não serem acolhedores em relação aos homens proporcionando um obstáculo e corroborando uma imagem de que esse local não é apropriado para o parceiro, tal fato é justificado pela ausência de instrumentos explicativos e decorativos exemplificando a figura paterna e reforçando sua participação no suporte pré-natal, desfazendo as contrariedades relacionada ao gênero. ${ }^{14}$

\section{Estratégias para adesão do pai no pré-natal do parceiro.}

As equipes de saúde devem encorajar a presença do homem/parceiro mesmo antes da gravidez, esse estímulo deve acontecer no planejamento familiar, que é um conjunto de ações que auxiliam homens e mulheres a planejar a chegada dos filhos. Infelizmente sabe-se que não é uma realidade no serviço de saúde. 
As principais estratégias apontadas nos estudos, para ampliar a adesão dos homens nos serviços de saúde são: criação de horários alternativos, como consultas no período da noite e aos sábados; a oferta de atividades educativas adequada para população masculina; ambientes receptivos, condutas acolhedoras ao parceiros de todas as faixas etárias de idade, principalmente aos adolescente; efetuação dos grupos para gestantes e seus acompanhantes ao apontar sobre as orientações no tocante aos direitos da mulher e do homem no período gravídico-puerperal, como por exemplo, a presença de um acompanhante durante o trabalho de parto e parto amparado pela Lei do Acompanhante, de $\mathrm{n}^{\circ} 11.108$ de 07 de abril de 2005. ${ }^{12,18,23}$

Um dos estudos propõe um quadro com fluxo de etapas e ações para envolvimento dos homens no prénatal. A primeira etapa, está relacionada ao acolhimento, deve dispor de discussões com os envolvidos sobre a participação do parceiro nas consultas de pré-natal, parto e puerpério, escuta sobre perspectivas em relação ao presente e futuro. A segunda etapa do estudo, refere a respeito da realização de testagem e atualização da caderneta vacinal, é importante assegurar e discutir com os envolvidos a efetivação destes para que possa ser proporcionado melhores condições de saúde dos mesmos e da criança. O próximo processo implica na supervisão e considerações sobre as consultas de pré-natal, referindo ser importante dialogar com os envolvidos sobre as mudanças e fatores estressores da gestação e a observação constante do comprometimento do casal e de como poderá implicar em sua saúde e na do bebê. Por último, discorre acerca do envolvimento do parceiro no parto e puerpério atendendo os desejos maternos. ${ }^{19}$

O meio cultural, regional e ambiental no qual homem está inserido pode causar influencia e proporcionar mudanças nos hábitos de vida. Além disso, em uma consulta de pré-natal, tradicionalmente os cuidados são voltados as mulheres, causando estranhamento do homem quando solicitado alguns procedimentos. Dessa forma, os profissionais de saúde necessitam de instrumentos que os auxiliem na comunicação com o paciente com o objetivo de envolvêlo na assistência. ${ }^{20}$

\section{Conclusão}

O estudo evidenciou que há vários fatores para a ausência do homem no acompanhamento do pré-natal da parceira e para adesão do pré-natal do pai. Os artigos estudados sugerem determinadas ações assistenciais a serem implementadas com vistas a modificar a circunstância atual.

Atualmente percebe-se maior interação do pai no período gravídico-puerperal, observado no desejo de envolver-se e estar preparado para a paternidade e o desejo da parceira de tê-lo por perto. Todavia, mesmo com os investimentos em saúde no tocante a atenção qualificada e humanizada, ainda é encontrado algumas objeções culturais e institucionais que impossibilitam o direito a atuação do pai desde o nascimento do filho.

Além disso, estimular a presença do parceiro durante o pré-natal, trabalho de parto, parto e puerpério, é uma forma de incentivar a atuação sobre sua saúde com vistas a se aproximar dos serviços de saúde, principalmente, da Atenção Primária.

Fica clara a necessidade do aprimoramento do acolhimento para esta população, adequação da estrutura física e ambiente para o atendimento do homem, implantação de horários alternativos, informar e conscientizar a população masculina sobre seus direitos, são estratégias de trabalho que se constrói o vínculo entre o usuário e o serviço de saúde e consequentemente ampliam a adesão do usuário aos serviços de saúde.

Portanto, sugere-se uma reorganização e reformulação no planejamento dos serviços de saúde para esta clientela, com vistas a promover a qualidade do atendimento, da saúde do homem e da adesão no pré-natal da parceira e no pré-natal do pai. Ainda que, os objetivos do trabalho tenham sido alcançados, é indispensável incentivar novos estudos referentes a temática.

\section{Referências}

1. Leite DA, Giuliani CD, Ferreira MC. Vivências do pai no pré-natal, pré-parto e parturição no século XXI. Uberlândia: Universidade Federal de Uberlândia; 2018.

2. Ministério da Saúde (BR). Cadernos de Atenção Básica Atenção ao Pré-Natal de Baixo Risco. Brasília, 2013.

3. Ministério da Saúde (BR). Portaria No 1.459, de 24 de junho de 2011. Institui, no âmbito do Sistema Único de Saúde - SUS - a Rede Cegonha. Diário Oficial da União, 2011.

4. Ministério da Saúde (BR). Programa de humanização do pré-natal e nascimento. Brasília; 2002

5. Ministério da Saúde (BR). Guia do Pré-Natal do Parceiro para Profissionais de Saúde. Rio de Janeiro; 2016.

6. Gianini S, de Oliveira PL, da Silva GSV. A presença do acompanhante no trabalho de parto, parto e pós-parto: compreensão das gestantes. Revista Pró-UniverSUS 11.1 (2020): 21-26

7. Mendes SC, dos Santos KCB. Pré-natal masculino: a importância da participação do pai nas consultas de pré-natal. Enciclopédia Biosfera, Centro Científico Conhecer-Goiânia 16.29 (2018).

8. Botelho LLR, Cunha CCA, Macedo M. O método da revisão integrativa nos estudos organizacionais. Gestão e sociedade 5.11 (2011): 121-136.

9. Lima-Costa MF, Barreto SM. Tipos de estudos epidemiológicos: conceitos básicos e aplicações na área do envelhecimento. Epidemiologia e serviços de saúde 12.4 (2003): 189-201.

10. Santos MA. Diálogos Metodológicos sobre prática de pesquisa. (1999): 95-99.

11. Mynaio MCS. Pesquisa Social Teoria, método e criatividade. $2^{\mathrm{a}}$. 
Edição. Rio de Janeiro: Vozes, 1993. 80p.

12. de Mello MG, Parauta TC, Saldanha BL, Lemos A. Participação do pai jovem no acompanhamento do pré-natal: a visão do profissional de saúde. Revista de Pesquisa: Cuidado é Fundamental. 2020: 94-99.

13. Cavalcanti TRL, de Holanda VR. Participação paterna no ciclo gravídico-puerperal e seus efeitos sob a saúde da mulher. Enferm. foco Brasília. 2019: 93-98.

14. Cardoso VES, Junior Bonatti AF, et al. A participação do parceiro na rotina pré-natal sob a perspectiva da mulher gestante. Rev. pesqui. cuid. fundam. (Online) 2018: 856-862.

15. Caldeira LA, et al. A visão das gestantes acerca da participação do homem no processo gestacional. Revista de Enfermagem do Centro-Oeste Mineiro 72017.

16. Costa SF, T SR. Atenção à Gestante Adolescente na Rede SUS-O acolhimento do parceiro no pré-natal. Rev. enferm. UFPE on line 2017: 2067-2074.

17. Lima JP, Cazola LHO, Picoli RP. A participação do pai no processo de amamentação. Cogitare enferm 22.1. 2017: 1-7.

18. Henz GS, Medeiros CRG, Salvadori, M. A inclusão paterna durante o pré-natal. 2018. Rev Enferm Atenção Saúde [Online]. Jan/Jun 2017; 6(1):5266.

19. Gomes R, et al. Linhas de cuidados masculinos voltados para a saúde sexual, a reprodução e a paternidade. Ciência \& Saúde Coletiva 21 2016: 1545-1552.

20. Moreira MCN, Gomes R, Ribeiro CR. E agora o homem vem?! Estratégias de atenção à saúde dos homens. Cadernos de Saúde Pública 32. 2016: e00060015.

21. Ministério da Saúde (BR). Protocolo Clínico e Diretrizes Terapêuticas para Atenção Integral às Pessoas com Infecções Sexualmente Transmissíveis IST. Brasília; 2020.

22. Brasil. Lei $\mathrm{N}^{\mathrm{o}} 13.257$, de 8 de março de 2016. Dispõe sobre as políticas públicas para a primeira infância e altera a Lei $n^{\circ} 8.069$, de 13 de julho de 1990 (Estatuto da Criança e do Adolescente), o Decreto-Lei ${ }^{\circ}$ 3.689, de 3 de outubro de 1941 (Código de Processo Penal), a Consolidação das Leis do Trabalho (CLT), aprovada pelo Decreto-Lei $\mathrm{n}^{\circ} 5.452$, de $1^{\circ}$ de maio de 1943, a Lei ${ }^{\circ} 11.770$, de 9 de setembro de 2008, e a Lei ${ }^{\circ} 12.662$, de 5 de junho de 2012. Diário da União. 08 de mar de 2016.

23. Brasil. Lei $\mathrm{N}^{\circ} 11.108$, de 7 de abril de 2005. Altera a Lei $\mathrm{N}^{\circ} 8.080$, de 19 de setembro de 1990, para garantir às parturientes o direito à presença de acompanhante durante o trabalho de parto, parto e pós-parto imediato, no âmbito do Sistema Único de Saúde - SUS. Diário da União. 08 de abril de 2005 . 